Животноводство и кормопроизводство 2020 T. 103 № 3/Animal Husbandry and Fodder Production 2020 Vol. 103 Is. 3 16 Нанотехнологии в животноводстве и кормопроизводстве

УДК 635.21:631.93

DOI: $10.33284 / 2658-3135-103-3-16$

Стрессоустойчивость растений Solanum tuberosum под влиянием УДЧ диоксида кремния

\author{
Е.В. Аминова, А.А. Мушинский, А.Ж. Саудабаева \\ Федеральный научный центр биологических систем и агротехнологий Российской академии наук (2. Оренбург)
}

\begin{abstract}
Аннотация. Интерес к использованию ультрадисперсных частиц в растениеводстве и практике сельского хозяйства связан, прежде всего, с их уникальными свойствами. В представленной работе дана оценка воздействия ультрадисперсных частиц диоксида кремния в различных концентрациях на растения Solanum tuberosum. Объектами исследования являлись клубни картофеля сорта «Тарасов». Образцы обрабатывали суспензией УдЧ $\mathrm{SiO}_{2}$ в концентрациях: 0,03, 0,09, 0,18, 0,21 и 0,36 г/кг картофеля. В ходе эксперимента была определена активность пероксидазы (по методу Бояркина), жизнеспособность клеток согласно протоколу производителя (WST-8 patent № 2.251.850, Канада) и целостность молекул ДНК растений Solanum tuberosum (из клеток растений методом фенол-хлороформной экстракции). Согласно результатам исследования, нанокремнезём в концентрации 0,21 и 0,36 г/кг оказал статистически значимое влияние на количество живых клеток (проявлялось снижение до 17,1 \%). Выявлено, что УДЧ диоксида кремния в концентрации 0,09 и 0,18 г/кг оказали значимое влияние на активность пероксидазы у растений Solanum tuberosum. Результаты проведённых исследований подтвердили уменьшение интенсивности пиков светимости ДНК темпорально рассчитанным линейным профилем при максимальном разведении 0,36 г/кг.

Ключевые слова: картофель, диоксид кремния, наночастицы, стрессоустойчивость картофеля, жизнеспособность клеток, целостность молекул ДНК.
\end{abstract}

UDC 635.21:631.93

\title{
Stress tolerance of Solanum tuberosum under the influence of silicon dioxide UFPs
}

Evgenia V Aminova, AlexanderA Mushinsky, Alia Zh Saudabaeva

Federal Research Centre of Biological Systems and Agrotechnologies of the Russian Academy of Sciences (Orenburg, Russia)

Summary. Interest in the use of ultrafine particles in crop production and agricultural practice is associated primarily with their unique properties. The presented work evaluates the impact of ultrafine particles of silicon dioxide in various concentrations on Solanum tuberosum. The objects of the study were potato tubers of the "Tarasov" variety and silicon dioxide UFPs. The samples were treated with a suspension of $\mathrm{SiO} 2$ UFPs at concentrations: $0.03,0.09,0.18,0.21$, and $0.36 \mathrm{~g} / \mathrm{kg}$ of potatoes. During the experiment, the peroxidase activity (according to Boyarkin's method), cell viability according to the manufacturer's protocol (WST-8 patent No. 2.251.850, Canada) and the integrity of the DNA molecules of Solanum tuberosum plants (from plant cells by phenol-chloroform extraction) were determined. According to the results of the study, nanosilica at a concentration of 0.21 and $0.36 \mathrm{~g} / \mathrm{kg}$ had a statistically significant effect on the number of living cells (there was a decrease to $17.1 \%$ ). It was revealed that the silicon dioxide UFPs at a concentration of 0.09 and $0.18 \mathrm{~g} / \mathrm{kg}$ had a significant effect on the peroxidase activity in Solanum tuberosum plants. The results of the studies carried out confirmed the decrease in the intensity of the DNA luminosity peaks by a temporally calculated linear profile at a maximum dilution of $0.36 \mathrm{~g} / \mathrm{kg}$.

Key words: potato, silicon dioxide, nanoparticles, potato stress resistance, cell viability, integrity of DNA molecules. 


\section{Введение.}

На сегодняшний день ультрадисперсные частицы (УДЧ) становятся важным продуктом инновационной науки и техники с широкими перспективами использования как в промышленности, так и в сельском хозяйстве. Недавние исследования в области изучения УдЧ кремния показали, что они могут непосредственно взаимодействовать с растениями и влиять на их морфологию и физиологию различными способами, включая добавление структурного цвета к растениям, а также способствовать улучшению роста растений и урожайности (Rastogi A et al., 2019).

Благодаря большой удельной поверхности УДЧ их использование в микродозах очень результативно, например, для того чтобы обработать одну тонну семян, необходимо всего несколько миллиграмм нанопорошка (Володина Л.А. и др., 2013).

Обработка семян растений УДЧ значительно увеличивает энергию прорастания, ростовую активность проростков и жизнеспособность растений, что способствует приумножению полученного урожая (Singh D et al., 2018; Маслоброд C.Н. и др., 2014).

Таким образом, в литературных источниках рассмотрено много экспериментов по оценке урожайности и биометрических параметров растений при использовании УДЧ (Tripathi DK et al., 2017; Rizwan M et al., 2017).

Всё более широкое применение наночастиц вызывает вопросы в связи с потенциальными экологическими последствиями, так как в окружающей среде УдЧ подвергаются физическим, химическим и биологическим преобразованиям под влиянием таких факторов, как почва, почвенные микроэлементы, биоты и т. д. Поэтому требуются детальные всесторонние исследования для определения экологически безопасного применения наноматериалов в сельском хозяйстве (Короткова A.M. и др., 2019; Lei C et al., 2018).

\section{Цель исследования.}

Изучение влияния ультрадисперсных частиц диоксида кремния на активность пероксидазы, жизнеспособность клеток и целостность молекул ДНК растений картофеля (Solanum tuberosum).

\section{Материалы и методы исследования.}

Объект исследования. Клубни картофеля сорта «Тарасов».

Схема эксперимента. Семенной материал был получен безвирусным размножением (in vitro) и передан в ФГБУ «Уральский федеральный аграрный исследовательский центр» УрО РАН (г. Челябинск). В исследованиях использовались наночастицы диоксида кремния (HЧ $\left.\mathrm{SiO}_{2}\right)$ размером 30,7 $\pm 0,3$ и z-потенциалом $27 \pm 0,12$ мB, полученные плазмохимическим синтезом (ООО «Передовые порошковые технологии», г. Томск, Россия).

Экспериментальное тестирование биологической активности НЧ $\mathrm{SiO}_{2}$ на клубнях картофеля проводилось на примере пяти концентраций диоксида кремния $(0,03,0,09,0,18,0,21$ и 0,36 г/кг клубней) в трёх повторностях. Суспензии НЧ $\mathrm{SiO}_{2}$ готовили согласно ТУ 931800-427076096.

Анализ жизнеспособности (ЖС) клеток по изменению ферментативной активности редуктаз осуществлялся согласно протоколу производителя (WST-8 patent № 2.251.850, Канада) с помощью высокочувствительного теста «Cell counting kit-8 (CKK-8)», основанного на использовании водорастворимой соли тетразолия (WST-8). Ультрадисперсные частицы диспергировали в ультрадисперсной ванне «Сапфир ТТЦ» при частоте 35 кГц в течение 30 минут.

Активность пероксидазы определяли по методу Бояркина, оптическую плотность при 580 нм в реакционной смеси: 0,5 мл 0,1 М цитратно-фосфатного буфера (pH 6,2 и 5,4), 0,5 мл 0,3 \% $\mathrm{H}_{2} \mathrm{O}_{2}$ и 0,5 мл $(0,035 \%, 0,04 \%, 0,045 \%, 0,5 \%, 0,055 \%)$ гваякола.

Выделение ДНК: 1000 мг корней разделяли на аликвоты по 250 мг, замораживали жидким азотом 5 мин, к образцам добавляли 450 мкл ТСБ буфера. Пробы встряхивали на гомогенизаторе «TissueLyser LT» в режиме: при частоте 50 Гц - 30 секунд и прогревали при +95 ${ }^{\circ} \mathrm{C} 10$ мин. 
Добавляли 10 \% SDS 50 мкл, протеиназа К 2 мкл. Встряхивали Microspin FV-2400 5 с. Инкубировали 30 мин при $+60{ }^{\circ} \mathrm{C}$. Добавляли фенол-хлороформную смесь (1:1) в равном объёме, т. е. 500 мкл. Центрифугировали 5 мин (14500 об./мин, Microspin 12). Отобрали водную фазу 400 мкл, добавили равный объём хлороформ изоамилового спирта. Центрифугировали (14500 об./мин, 5 мин). Отобрали водную фазу 350 мкл, добавили 40 мкл 10М ацетата аммония (10:1) и 1000 мкл ледяного абсолютного спирта $\left(-20{ }^{\circ} \mathrm{C}\right)$. Для осаждения ДНК оставили на ночь в морозилке $\left(-20{ }^{\circ} \mathrm{C}\right)$. Центрифугировали 30 мин при $+4{ }^{\circ} \mathrm{C}, 14000$ об./мин. Убрали спирт и добавили 400 мкл $80 \%$ холодного этилового спирта. Центрифугировали 10 мин при $+4{ }^{\circ} \mathrm{C}, 14000$ об./мин,, затем добавили 30-50 мкл MQ.

Оборудование и технические средства. Все лабораторные анализы проводились в аккредитованной лаборатории Испытательного центра ЦКП ФНЦ БСТ РАН (аттестат аккредитации № RA.RU.21ПФ59 от 02.12.15). Тест «Cell counting kit-8 (CKK-8)» («Sigma-Aldrich», США), ультрадисперсная ванна «Сапфир ТТЦ» («НТК Солтек», Россия), гомогенизатор «TissueLyser LT» («Qiagen», Германия), центрифуги Microspin FV-2400 («BIOSAN», Латвия), Microspin 12 («BIOSAN», Латвия).

Статистическая обработка. Полученные результаты обрабатывали методами вариационной статистики с помощью офисного программного комплекса «Microsoft Office» с применением программы «Excel» («Microsoft», США) с обработкой данных в программе «Statistica 10.0» («Stat Soft Inc.», США). Достоверными считали результаты $\mathrm{P} \leq 0,05$.

\section{Результаты исследований.}

Пероксидаза является индикатором стрессового состояния, именно она может объективно характеризовать защитные реакции устойчивости клеток растений к стрессовым факторам. При обработке клубней картофеля $\mathrm{HЧ} \mathrm{SiO}_{2}$ в концентрации 0,09 и 0,18 г/кг увеличилась активность пероксидазы в сравнении с контролем в 2 раза и составила 532,9 и 513,2 условн. ед./Г сырой массы соответственно. В остальных вариантах активность фермента варьировала от 224,8 до 461,8 условн. ед./Г сырого веса (рис. 1).

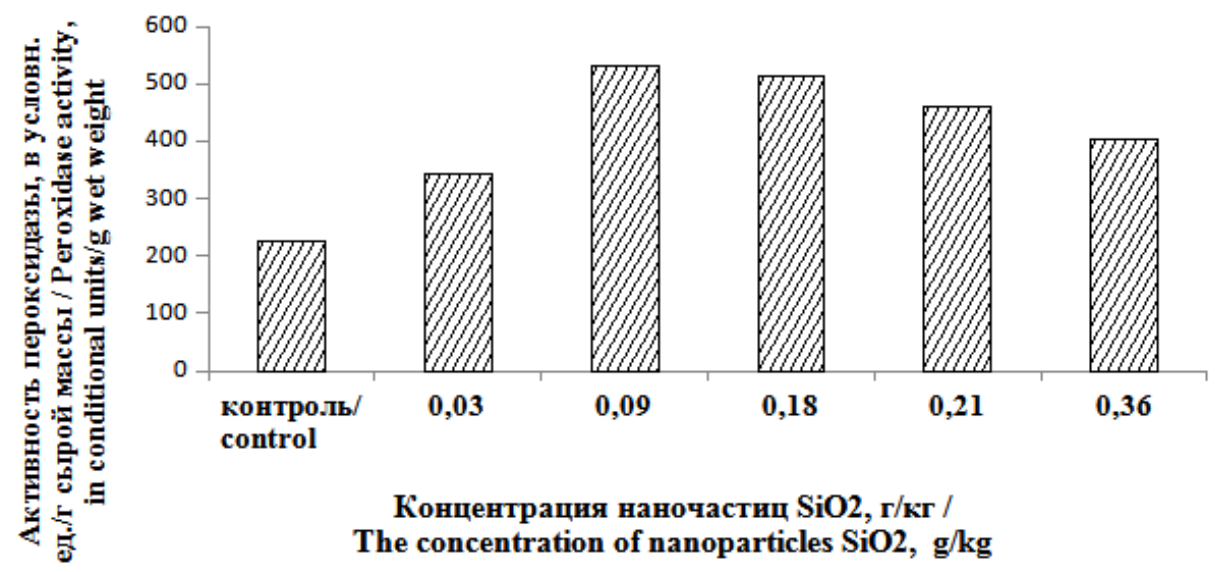

Рис. 1 - Активность пероксидазы ростков Solánum tuberósum после воздействия ${\mathrm{HЧ} \mathrm{SiO}_{2}}_{2}$ выражена в условн. ед./г сырой массы, при достоверных значениях $\mathbf{P} \leq 0,05$

Figure 1 - The peroxidase activity of Solánum tuberósum sprouts after exposure to $\mathrm{SiO}_{2} \mathrm{NPs}$ is expressed in relative conditionally units/g raw mass, with significant values of $P \leq 0.05$

В ходе эксперимента мы оценивали жизнеспособность клеток (ЖС) по выходу формазана из водорастворимой соли тетразолия. Наличие в среде $\mathrm{SiO}_{2}$ в концентрациях 0,21 и 0,36 г/кг приводило к снижению содержания формазана на 24 ч инкубации (до 17,1 \% относительно контроля), а на остальных концентрациях $(0,03,0,09,0,18$ г/кг) увеличение активности редуктаз было несущественным (до 5,2 \%) (рис. 2). 


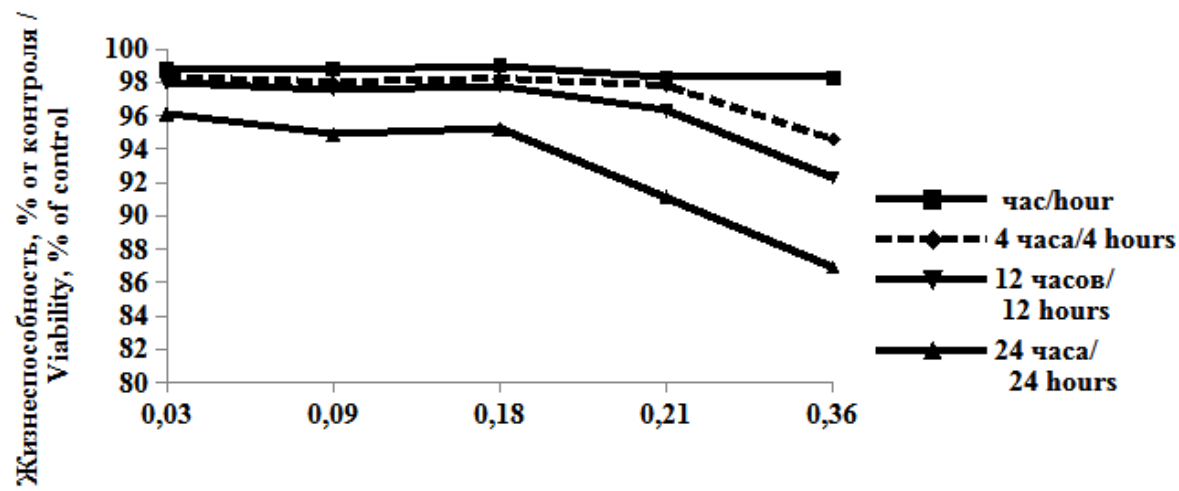

Концентрация наночастиц $\mathrm{SiO} 2$ /

The concentration of nanoparticles $\mathrm{SiO} 2, \mathrm{~g} / \mathrm{kg}$

Рис. 2 - Жизнеспособность клеток корней Solánum tuberósum после воздействия НЧ $\mathrm{SiO}_{2}$ Figure 2 - Viability of Solánum tuberósum root cells after exposure $\mathrm{SiO}_{2} \mathrm{NPs}$

Анализ электрофоретической мобильности фракции ДНК, выделенных из корней картофеля после экспонирования с диоксидом кремния, не показал выраженной деградации молекул. Особенностью воздействия $\mathrm{HЧ} \mathrm{SiO}_{2}$ было лишь прямо пропорциональное уменьшение общего содержания ДНК, визуализируемого на электрофореграмме в виде снижения интенсивности флуоресценции до 86 \%.

В результате проведённых исследований деградация молекул подтверждается темпорально рассчитанными линейными профилями (рис. 3), на которых отчётливо видно уменьшение интенсивности пиков светимости ДНК в случае с максимальным разведением - 0,36 г/кг и нарастающие пики, приближающиеся к контрольному варианту - в случае концентраций 0,18 и 0,03 г/кг.

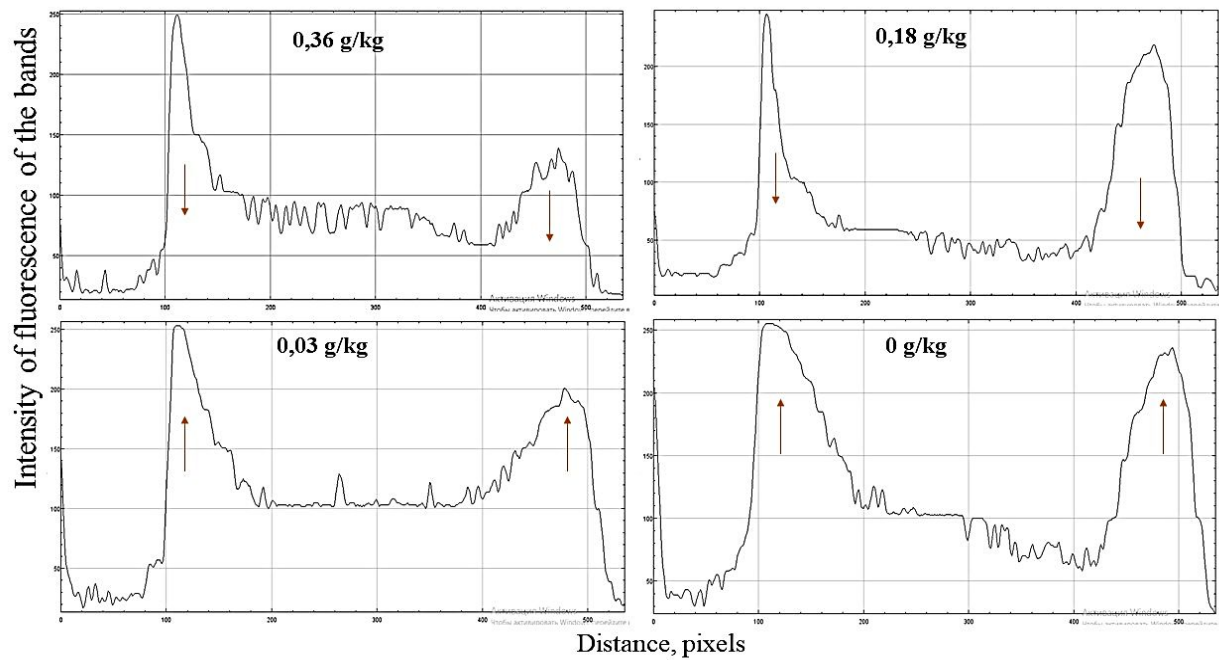

Рис. 3 - Линейные профили полос электрофореграммы ДНК, выделенной из корней Solánum tuberósum после воздействия НЧ $\mathrm{SiO}_{2}$ в концентрациях 0,36, 0,18, 0,03 г/кг в течение 72 часов

Figure 3 - Linear profiles of bands of an electrophoretogram of DNA isolated from the roots of Solánum tuberósum after exposure to $\mathrm{SiO}_{2} \mathrm{NPs}$ at concentrations of $0.36,0.18$, $0.03 \mathrm{~g} / \mathrm{kg}$ for 72 hours 


\section{Обсуждение полученных результатов.}

За последние десятилетия ведущими мировыми учёными опубликовано достаточно научных работ по фитотоксичности УДЧ, которые могут вызывать окислительный стресс у разных видов растений (Dimkpa CO et al., 2012; Ma C et al., 2016). Так, Roohizadeh G c коллегами (2015) показали, что диоксид кремния в концентрации 1,5 и 3 мМ значительно увеличивал активность пероксидазы у растений Vicia faba L, что, в свою очередь, приводит к меньшему ущербу, в отличие от АФК, и защищает растения от стресса. В нашем эксперименте также под воздействием наночастиц $\mathrm{SiO}_{2}$ в концентрации 0,09 и 0,18 г/кг увеличилась активность пероксидазы в 2 раза, что согласуется с вышеупомянутой работой.

Молекула ДНК является генетическим материалом клетки, и любое повреждение ДНК вызовет изменения в закодированных белках, которые могут привести к сбоям или полной инактивации кодированных белков. Повышенная деградация ДНК наблюдалась у растений, подвергающихся воздействию таких видов экологических стрессов, как металлические УДЧ и углеродные наноматериалы (Lopes S et al., 2016). Также интересно отметить и то, что многие авторы (Алёшин Н.Е. и др., 1982, Воронков М.Г. и др., 1978; Belanger MC, 2005; Ma C et al., 2016; Hassan E et al., 2018) в своих исследованиях наблюдали сбалансированность кремниевого питания, которая повышает стабильность молекул ДНК и РНК. Ими заявлена гипотеза, что атом кремния может встраиваться в нуклеиновые кислоты и повышать их устойчивость к стресс-факторам. В последующем мы решили оценить и проанализировать последствия прямого контакта УДЧ $\mathrm{SiO}_{2}$ с ДНК растений картофеля после 72 часов. Результаты исследований подтвердили уменьшение интенсивности пиков светимости ДНК темпорально рассчитанным линейным профилем при максимальном разведении 0,36 г/кг (рис. 3). Аналогичный результат прослеживался в работе Матыченкова И.В. (2014), когда при дозах внесения 100, 300, 500 и 700 кг/га аморфного кремнезёма уменьшалось содержание ДНК до величин $112,3 \pm 0,8 ; 119,0 \pm 0,6 ; 120,3 \pm 0,7$ и $124,1 \pm 0,3$ соответственно.

Согласно результатам нашего эксперимента, диоксид кремния в концентрации 0,21 и 0,36 г/кг оказал статистически значимое влияние на количество живых клеток (снижение до 17,1 \%).

\section{Выводы.}

В результате исследований воздействия УдЧ диоксида кремния на растения Solánum tuberósum нами установлено, что $\mathrm{SiO}_{2}$ оказывал влияние на активность пероксидазы при концентрации 0,09 и 0,18 г/кг.

Снижение жизнеспособности клеток корней наблюдалось в большей степени при концентрации 0,21 и 0,36 г/кг и вызывало угнетение формазана до $17,1 \%$ относительно контроля на 24 ч инкубации.

Согласно результатам исследования, линейные профили образцов свидетельствуют об отсутствии видимой деградации ДНК.

Исследования выполнены в соответствии с планом НИР на 2019-2021 гг. ФГБНУ ФНЦ БСТ РАН (№ 0761-2019-0011)

\section{Литература}

1. Алёшин Н.Е., Авакян А.П., Алешин Е.П. Содержание Si в ДНК риса. Доклады ВАСХНИЛ, 1982. № 6. С. 6-7. [Alechin NE, Avakyan AP, Alechin EP. Soderzhanie Si v DNK risa. Dokl VASHNIL; 1982;6:6-7. (In Russ)].

2. Влияние водных дисперсных систем с наночастицами серебра и меди на прорастание семян / С.Н. Маслоброд, Ю.А. Миргород, В.Г. Бородина, Н.А. Борщ // Электронная обработка материалов. 2014. № 50(4) С. 103-112. [Maslobrod SN, Mirgorod YuA, Borodina VG, Borshch NA. 
Vliyanie vodnyh dispersnyh system s nanochastitsami serebra i medi na prorastanie semyan. Elekronnaya obrabotka materialov. 2014;50(4):103-112. (In Russ)].

3. Влияние физико-химических характеристик модифицированных поверхностей наноразмерных частиц меди на ингибирование роста культуры клеток Escherichia coli и электростатические свойства поверхности бактерий / Л.А. Володина, А.Н. Жигач, И.О. Лейпунский, Е.С. Зотова, Н.Н. Глущенко // Биофизика. 2013. № 58(3). С. 507-515. [Volodina LA, Zhigach AN, Leypunsky IO, Zotova ES, Glushchenko NN. The influence of physical-chemical characteristics of surface modified copper nanoparticles on E. coli cell population growth suppression and on electrostatic properties of their membranes. Biophysics. 2013;58(3):394-401. (In Russ)].

4. Воронков М.Г., Зельчан Г.И., Лукевиц Э.Я. Кремний и жизнь: Биохимия, фармокология и токсикология соединений кремния. 2-е изд., перераб. и доп. Рига: Зинатне, 1978. 587 с. [Voronkov MG, Zel'chan GI, Lukevits EYa. Kremnii i zhizn': Biokhimiya, farmokologiya i toksikologiya soedinenii kremniya. 2-e izd., pererab. i dop. Riga: Zinatne; 1978:587 p. (In Russ)].

5. Матыченков И.В. Взаимное влияние кремниевых, фосфорных и азотных удобрений в системе почва-растение: дис. ... канд. биол. наук. М., 2014. 136 с. [Matychenkov IV. Vzaimnoe vliyanie kremnievykh, fosfornykh i azotnykh udobrenii v sisteme pochva-rastenie. [dissertation] Moscow; 2014:136 p. (In Russ)].

6. Оценка влияния ультрадисперсных частиц на биометрические параметры проростков пшеницы / А.М. Короткова, С.В. Лебедев, О.В. Кван, К.Н. Атландерова // Животноводство и кормопроизводство. 2019. Т. 102. № 2. С. 7-20. [Korotkova AM, Lebedev SV, Kvan OV, Atlanderova KN. Evaluation of ultrafine particles influence on biometric parameters of wheat germs. Animal Husbandry and Fodder Production. 2019;102(2):7-20. (In Russ)]. doi: 10.33284/2658-3135-102-2-7

7. Belanger MC, Ouellet M, Queney G, Moreau M. Taurine-deficient dilated cardiomyopathy in a family of golden retrievers. J Am Anim Hosp Assoc. 2005;41(5):284-291. doi: 10.5326/0410284

8. Dimkpa CO, McLean JE, Latta DE, Manangón E, Britt DW, Johnson WP, Boyanov MI, Anderson $\mathrm{AJ}$. $\mathrm{CuO}$ and $\mathrm{ZnO}$ nanoparticles: phytotoxicity, metal speciation, and induction of oxidative stress in sand-grown wheat. J Nanopart Res. 2012;14:1125. doi: https://doi.org/10.1007/s11051-012-1125-9

9. Hassan E, Byoung RJ. Silicon (Si): Review and future prospects on the action mechanisms in alleviating biotic and abiotic stresses in plants. Ecotoxicology and Environmental Safety. 2018;147:881896. doi: https://doi.org/10.1016/j.ecoenv.2017.09.063

10. Lei C, Sun Y, Tsang DCW, Lin D. Environmental transformations and ecological effects of ironbased nanoparticles. Environmental Pollution. 2018;232:10-30. doi: https://doi.org/10.1016/j.envpol.2017.09.052

11. Lopes S, Pinheiro C, Soares AMVM, Loureiro S. Joint toxicity prediction of nanoparticles and ionic counterparts: Simulating toxicity under a fate scenario. Journal of Hazardous Materials. 2016;320:1 9. doi: https://doi.org/10.1016/j.jhazmat.2016.07.068

12. Ma C, Liu H, Guo H, Musante C, Coskun SH, Nelson BC, White JC, Xing B, Dhankher OP. Defense mechanisms and nutrient displacement in Arabidopsis thaliana upon exposure to $\mathrm{CeO}_{2}$ and $\mathrm{In}_{2} \mathrm{O}_{3}$ nanoparticles. Environ Sci: Nano. 2016;3:1369-1379. doi: http://doi:10.1039/C6EN00189K

13. Rastogi A, Tripathi DK, Yadav S et al. Application of silicon nanoparticles in agriculture. Biotech. 2019;9:90. doi: https://doi.org/10.1007/s13205-019-1626-7

14. Rizwan M, Ali S, Qayyum MF, Ok YS, Adrees M, Ibrahim M, Zia-ur-Rehman M, Farid M, Abbas F. Effect of metal and metal oxide nanoparticles on growth and physiology of globally important food crops: A critical review. J Hazard Mater. 2017;322 (Part A):2-16. doi: https://doi.org/10.1016/j.jhazmat.2016.05.061

15. Roohizadeh G, Arbabian S, Tajadod G, Majd A, Salimpour F. The study of Nano silica effects on the total protein content and the activities of catalase, peroxidase and superoxid dismutase of Vicia faba L. Trop Plant Res. 2015;2(1):47-50.

16. Singh D, Kumar A. Investigating long-term effect of nanoparticles on growth of Raphanus sativus plants: a trans-generational study. Ecotoxicology. 2018;27(1):23-31. doi: https://doi.org/10.1007/s10646-017-1867-3 
17. Tripathi DK, Shweta, Singh S, Singh S, Pandey R, Singh VP, Sharma NC, Prasad SM, Dubey NK, Chauhan DK. An overview on manufactured nanoparticles in plants: Uptake, translocation, accumulation and phytotoxicity. Plant Physiology and Biochemistry. 2017;110:2-12. doi: 10.1016/j.plaphy.2016.07.030

\section{References}

1. Alechin NE, Avakyan AP, Alechin EP. Si content in rice DNA. Dokl. VASKHNIL. 1982;6:6-7.

2. Maslobrod SN, Mirgorod YuA, Borodina VG, Borshch NA. Influence of water dispersed systems with silver and copper nanoparticles on seed germination. Electronic Processing of Materials. 2014;50(4):103-112.

3. Volodina LA, Zhigach AN, Leypunsky IO, Zotova ES, Glushchenko NN. The influence of physical-chemical characteristics of surface modified copper nanoparticles on E. coli cell population growth suppression and on electrostatic properties of their membranes. Biophysics. 2013;58(3):394-401.

4. Voronkov MG, Zelchan GI, Lukevits EYa. Silicon and Life: Biochemistry, Pharmacology and Toxicology of Silicon Compounds. 2nd ed., rev. and add. Riga: Zinatne;1978:587 p.

5. Matychenkov IV. Mutual influence of silicon, phosphoric and nitrogen fertilizers in the soilplant system. [dissertation] Moscow; 2014:136 p.

6. Korotkova AM, Lebedev SV, Kvan OV, Atlanderova KN. Evaluation of ultrafine particles influence on biometric parameters of wheat germs. Animal Husbandry and Fodder Production. 2019;102(2):7-20. doi: 10.33284/2658-3135-102-2-7

7. Belanger MC, Ouellet M, Queney G, Moreau M. Taurine-deficient dilated cardiomyopathy in a family of golden retrievers. J Am Anim Hosp Assoc. 2005;41(5):284-291. doi: 10.5326/0410284

8. Dimkpa CO, McLean JE, Latta DE, Manangón E, Britt DW, Johnson WP, Boyanov MI, Anderson $\mathrm{AJ} . \mathrm{CuO}$ and $\mathrm{ZnO}$ nanoparticles: phytotoxicity, metal speciation, and induction of oxidative stress in sand-grown wheat. J Nanopart Res. 2012;14:1125. doi: https://doi.org/10.1007/s11051-012-1125-9

9. Hassan E, Byoung RJ. Silicon (Si): Review and future prospects on the action mechanisms in alleviating biotic and abiotic stresses in plants. Ecotoxicology and Environmental Safety. 2018;147:881896. doi: https://doi.org/10.1016/j.ecoenv.2017.09.063

10. Lei C, Sun Y, Tsang DCW, Lin D. Environmental transformations and ecological effects of ironbased nanoparticles. Environmental Pollution. 2018;232:10-30. doi: https://doi.org/10.1016/j.envpol.2017.09.052

11. Lopes S, Pinheiro C, Soares AMVM, Loureiro S. Joint toxicity prediction of nanoparticles and ionic counterparts: Simulating toxicity under a fate scenario. Journal of Hazardous Materials. 2016;320:19. doi: https://doi.org/10.1016/j.jhazmat.2016.07.068

12. Ma C, Liu H, Guo H, Musante C, Coskun SH, Nelson BC, White JC, Xing B, Dhankher OP. Defense mechanisms and nutrient displacement in Arabidopsis thaliana upon exposure to $\mathrm{CeO}_{2}$ and $\mathrm{In}_{2} \mathrm{O}_{3}$ nanoparticles. Environ Sci: Nano. 2016;3:1369-1379. doi: http://doi:10.1039/C6EN00189K

13. Rastogi A, Tripathi DK, Yadav S et al. Application of silicon nanoparticles in agriculture. Biotech. 2019;9:90. doi: https://doi.org/10.1007/s13205-019-1626-7

14. Rizwan M, Ali S, Qayyum MF, Ok YS, Adrees M, Ibrahim M, Zia-ur-Rehman M, Farid M, Abbas F. Effect of metal and metal oxide nanoparticles on growth and physiology of globally important food crops: A critical review. J Hazard Mater. 2017;322 (Part A):2-16. doi: https://doi.org/10.1016/j.jhazmat.2016.05.061

15. Roohizadeh G, Arbabian S, Tajadod G, Majd A, Salimpour F. The study of Nano silica effects on the total protein content and the activities of catalase, peroxidase and superoxid dismutase of Vicia faba L. Trop Plant Res. 2015;2(1):47-50.

16. Singh D, Kumar A. Investigating long-term effect of nanoparticles on growth of Raphanus sativus plants: a trans-generational study. Ecotoxicology. 2018;27(1):23-31. doi: https://doi.org/10.1007/s10646-017-1867-3

17. Tripathi DK, Shweta, Singh S, Singh S, Pandey R, Singh VP, Sharma NC, Prasad SM, Dubey NK, Chauhan DK. An overview on manufactured nanoparticles in plants: Uptake, translocation, accumulation and phytotoxicity. Plant Physiology and Biochemistry. 2017;110:2-12. doi: 10.1016/j.plaphy.2016.07.030 
Аминова Евгения Владимировна, кандидат сельскохозяйственных наук, ведущий научный сотрудник отдела картофелеводства, Федеральный научный центр биологических систем и агротехнологий Российской академии наук, 460051, г. Оренбург, пр. Гагарина, 27/1, тел.: 89128411931, e-mail: aminowa.eugenia2015@yandex.ru

Мушинский Александр Алексеевич, доктор сельскохозяйственных наук, ведущий научный сотрудник, Федеральный научный центр биологических систем и агротехнологий Российской академии наук, 460051, г. Оренбург, пр. Гагарина, 27/1, тел.: 89058193592, e-mail: san2127@yandex.ru

Саудабаева Алия Жонысовна, кандидат биологических наук, научный сотрудник отдела картофелеводства, Федеральный научный центр биологических систем и агротехнологий Российской академии наук, 460000, 460051, г. Оренбург, пр. Гагарина, 27/1, тел.: 89128411931, e-mail: aleka_87@bk.ru

Поступила в редакцию 3 сентября 2020 г.; принята после решения редколлегии 14 сентября 2020 г.; опубликована 30 сентября 2020 г. / Received: 3 September 2020; Accepted: 14 September 2020; Published: 30 September 2020 